\title{
Correction: Ingenbleek, L. et al. Regional Sub-Saharan Africa Total Diet Study in Benin, Cameroon, Mali, and Nigeria Reveals the Presence of 164 Mycotoxins and Other Secondary Metabolites in Foods
}

\author{
Luc Ingenbleek $\left.{ }^{1,2}{ }^{(}\right)$, Michael Sulyok ${ }^{3}{ }^{(0)}$, Abimbola Adegboye ${ }^{4}$, Sètondji Epiphane Hossou ${ }^{5}$, \\ Abdoulaye Zié Koné ${ }^{6}$, Awoyinka Dada Oyedele ${ }^{4}$, Chabi Sika K. J. Kisito ${ }^{7}$, \\ Yara Koreissi Dembélé ${ }^{8}$, Sara Eyangoh ${ }^{1}$, Philippe Verger ${ }^{9}$, Jean-Charles Leblanc ${ }^{10, *}$, \\ Bruno Le Bizec ${ }^{2}$ (D) and Rudolf Krska ${ }^{3,11}$ (D) \\ 1 Centre Pasteur du Cameroun (CPC), BP1274 Yaoundé, Cameroon; luc.ingenbleek@gmail.com (L.I.); \\ eyangoh@pasteur-yaounde.org (S.E.) \\ 2 LABERCA, Oniris, INRA, 44307 Nantes, France; Bruno.LeBizec@oniris-nantes.fr \\ 3 Department IFA-Tulln, University of Natural Resources and Life Sciences, Vienna (BOKU), 3430 Tulln, \\ Austria; michael.sulyok@boku.ac.at (M.S.); Rudolf.Krska@boku.ac.at (R.K.) \\ 4 National Agency for Food and Drug Administration and Control (NAFDAC), 900288 Abuja, Nigeria; \\ adegboye.a@nafdac.gov.ng (A.A.); oyedele.dada@nafdac.gov.ng (A.D.O.) \\ 5 Agence Béninoise de Sécurité Sanitaire des Aliments (ABSSA), BP 362 Cotonou, Benin; hossepfr@yahoo.fr \\ 6 Agence Nationale de la Sécurité Sanitaire des Aliments (ANSSA), BP 2362 Bamako, Mali; \\ ngolona@gmail.com \\ 7 Laboratoire Central de Sécurité Sanitaire des Aliments (LCSSA), BP 6874 Cotonou, Benin; \\ kinnousika@yahoo.fr \\ 8 Laboratoire de Technologie Alimentaire (LTA), BP 258 Bamako, Mali; ykoreissidemb@gmail.com \\ 9 World Health Organization (WHO), 1211 Geneva, Switzerland; vergerp@who.int \\ 10 Food and Agriculture Organization of the United Nations (FAO), 00153 Rome, Italy \\ 11 Institute for Global Food Security, School of Biological Sciences, Queens University Belfast, Belfast BT7 1NN, \\ Northern Ireland, UK \\ * Correspondence: JeanCharles.Leblanc@fao.org
}

Received: 20 February 2019; Accepted: 26 February 2019; Published: 28 February 2019

The authors wish to make the following corrections to their paper [1].

In the author contributions section, "The first draft was produced by L.I. and M.S. and was then reviewed by R.K. and J.-C.L. Technical support was provided by J.-C.L., A.A., P.V. and B.L.B. National coordination including sample collection was assured by A.A., A.Z.K., S.E.H., and S.E. Food preparation was supervised by A.D.O., C.S.K.J.K., Y.K.D. and L.I., M.S. and R.K. supervised laboratory tests." should be replaced with "The first draft was produced by L.I. and M.S. and was then reviewed by R.K., A.A., and J.-C.L. Technical support was provided by J.-C.L., P.V., and B.L.B. National coordination, including sample collection, was assured by A.A., A.Z.K., S.E.H., and S.E. Food preparation was supervised by A.D.O., C.S.K.J.K., Y.K.D., and L.I. M.S. and R.K. supervised laboratory tests. The views expressed in this publication are those of the authors and do not necessarily reflect the views and policies of the Food and Agriculture Organization of the United Nations."

In the copyright section, "(C 2019 by the authors. Licensee MDPI, Basel, Switzerland. This article is an open access article distributed under the terms and conditions of the Creative Commons Attribution (CC BY) license (http:/ / creativecommons.org/licenses/by/4.0/)." should be replaced with "@ 2019 by Food and Agriculture Organization of the United Nations; licensee MDPI, Basel, Switzerland." 
We apologize for any inconvenience caused to our readers.

\section{Reference}

1. Ingenbleek, L.; Sulyok, M.; Adegboye, A.; Hossou, S.E.; Koné, A.Z.; Oyedele, A.D.; K. J. Kisito, C.S.; Koreissi Dembélé, Y.; Eyangoh, S.; Verger, P.; et al. Regional Sub-Saharan Africa Total Diet Study in Benin, Cameroon, Mali and Nigeria Reveals the Presence of 164 Mycotoxins and Other Secondary Metabolites in Foods. Toxins 2019, 11, 54. [CrossRef] [PubMed] 